\title{
A HOSPITALIDADE COMO ASPECTO FACILITADOR EM AULAS DE LEM
}

\author{
Hospitality as a facilitating aspect at Modern Foreign Languages Classes
}

\author{
${ }^{24}$ CALADO, Prila Leliza
}

\begin{abstract}
RESUMO: O objetivo do presente trabalho é refletir acerca de algumas experiências do aluno de LEM em sala de aula, considerando que esse aluno assume um papel de estrangeiro em relação ao professor, falante da língua. Tais experiências, dentre outras, seriam: pedir ajuda, fazer perguntas, tirar dúvidas em uma língua que não é a sua materna; fazer questionamentos, indagações sobre o ambiente que não é o seu "original", "natural" e como isso se dá em sala de aula. Para analisar tais situações / problemas, tomou-se por base o livro "Anne Dufourmantelle convida Jacques Derrida a falar da hospitalidade", o qual nos apresenta reflexões sobre o estrangeiro, quem é o estrangeiro, como ele se comporta e o que se espera quando assume essa posição. $\mathrm{O}$ livro nos traz também, a noção de hospitalidade, supostamente sempre oferecida pelos hospedeiros, mas nem sempre de maneira "automática". Em sala de aula a noção de hospitalidade entraria para amenizar o sentimento de exclusão e vergonha que o aluno muitas vezes pode sentir. Mas como isso acontece na prática? Quais procedimentos o professor é suposto utilizar para fazer com que o aluno se sinta bem, aprenda o novo idioma efetivamente e se sinta motivado a frequentar as aulas? PALAVRAS-CHAVE: hospitalidade; estrangeiro; heterogeneidade, pós-
\end{abstract} estruturalismo, LEM

ABSTRACT: The aim of this paper is to reflect on some experiences of FL (foreign language) students in the classroom, considering that students can act as foreigners in relation to the teacher, speaker of the language. These experiences, among others, would be: to ask for help, to ask questions, to answer questions in a language which is not their mother tongue, to ask questions, inquiries about the environment that is not their "original", "natural" one and how it happens in the classroom. To analyze such situations / problems, the book "On Hospitality," by Anne Dufourmantelle was taken, and it presents reflections on the foreigner, who is the foreigner, how s/he behaves and what s/he expects when takes such a role. The book also brings in the notion of hospitality, always allegedly offered by the hosts, but not always so "automatically." In the classroom the notion of hospitality would appear to alleviate the feelings of exclusion and shame that the student can often feel. But how does it happen in practice? Which procedures is the teacher supposed to use to make the student feel good, learn a new language effectively and feel motivated to attend classes?

KEYWORDS: hospitality; foreigner; heterogeneity, post-structuralism, FL

O objetivo do presente ensaio é refletir acerca de algumas situações vivenciadas por alunos e professores de Língua Estrangeira Moderna (LEM), as quais podem causar déficit de aprendizado, traumas relacionados à língua estrangeira e desmotivação para

\footnotetext{
${ }^{24}$ Especialização em Ensino de Língua Inglesa e Tradução (PUC - PR).
} 
aprender um novo idioma, considerando que muitas vezes o aluno pode vir a assumir um papel de estrangeiro em relação ao professor (falante da língua) e a outros colegas mais adiantados na disciplina. Quando observamos aulas de LEM é comum perceber por parte do aluno um sentimento de vergonha, de constrangimento e até mesmo de medo de enfrentar as atividades propostas pelo professor. Uma sensação de desconforto, de estar perdido, de não se adaptar àquele contexto que frequentemente impede ou prejudica o aprendizado e a evolução do aluno. É normal verificar que muitos estudantes iniciam repetidas vezes o curso de idiomas sempre com o mesmo discurso: "Não consigo aprender", "Termino o nível básico e não consigo avançar", "Perdi as contas de quantas vezes já cursei o nível básico”. Sentimentos como esses representam barreiras gigantescas para quem precisa, mas não consegue avançar no aprendizado e na aquisição de um novo idioma. Consequentemente, tais situações levam muitos alunos à desistência definitiva do objetivo de aprender uma nova língua, já que não obtiveram êxito mesmo depois de repetidas tentativas.

Ao ler o texto "A Fábula das Abelhas" do médico holandês Bernard de Mandeville, escrita em 1723, é possível perceber a convicção do autor sobre a ideia de que o homem não possui razões para ajudar o outro, a menos que possa se beneficiar de algum modo com tal ação. Não há boas intenções em atitudes tomadas em prol do próximo e o desejo humano na busca do autointeresse teria como consequência não intencional um caráter estabilizador para a sociedade. A Fábula conta, de forma irônica, como os vícios de cada abelha em particular eram vitais para o sucesso econômico da colmeia como um todo. No entanto, pregando como ideal as virtudes e condenando os vícios, as abelhas acabaram tendo seu pedido atendido, e seu deus colocou um fim aos vícios. Todos se tornaram virtuosos. Mas não foi preciso muito tempo para que o desemprego começasse a surgir em larga escala, e a economia da colmeia ficasse totalmente estagnada. Mandeville pretende mostrar a importância dos vícios, mas deixa claro que, apesar desses serem inseparáveis das grandes sociedades, e que é impossível à riqueza sobreviver sem eles. Os membros particulares da sociedade que são culpados de algum vício devem ser reprovados ou mesmo punidos quando viram crimes. Ou seja: se aceita que os vícios são a força motora do crescimento econômico, mas nem por isso deixa-se de combater seus excessos.

Um dos grandes pensadores que criticou a obra de Mandeville foi Adam Smith. Em “Teoria dos Sentimentos Morais”, obra publicada em 1759 (1999, p. 210), ele diz: "O Dr. Mandeville considera que tudo o que se faz por senso de conveniência, por 
respeito ao que é recomendável e louvável, se faz por amor ao louvor e à aprovação, ou, como ele diz, por vaidade." O que existe é a preocupação com o que os outros dirão, a imagem do indivíduo perante seu meio de convivência, já que, na perspectiva de Mandeville, o homem está muito mais interessado em sua própria felicidade do que na dos outros, e que é impossível, em seu foro íntimo, preferir realmente a prosperidade desses à sua própria. Quando aparenta preferir a felicidade dos outros, podemos estar certos de que está agindo motivado por desejos egoístas. Dentre todos os vícios, a vaidade é um dos mais fortes, levando sempre o indivíduo a ficar facilmente lisonjeado com os elogios que recebe.

Três séculos após a publicação da "Fábula das Abelhas", com o lançamento do livro “Anne Dufourmantelle convida Jacques Derrida a falar da hospitalidade” (2003) é possível estabelecer um paralelo e constatar que, para o filósofo francês Jacques Derrida, a atitude do homem deveria ser totalmente contrária ao descrito pelo médico holandês no século XVIII. Mas será possível ? O livro de Anne Dufourmantelle é uma entrevista durante a qual Jacques Derrida discursa sobre o estrangeiro, o indivíduo que ao estar fora de seu país ou cidade precisa contar com a abertura do hospedeiro, do nativo daquele novo lugar; precisa contar com a hospitalidade do povo desse novo ambiente, que, por sua vez, deveria abrir sem maiores preocupações ou ponderações as portas de sua casa ao novo habitante, sem esperar nada em troca.

Ao entrar nesse novo meio, o estrangeiro muitas vezes possui o desejo de querer igualar-se ao nativo, tornar-se algo superior. Entretanto, quando depara-se com as dificuldades e diferenças do novo ambiente, frustra-se de tal maneira que por vezes assume um papel menor, inferior, como se fosse impossível igualar-se ao nativo. Uma outra consequência desse sentimento de frustração é que esse indivíduo estrangeiro faz muitas perguntas, questiona e se opõe a determinadas regras e situações as quais não está habituado ou com as quais não concorda. Quer se tornar um nativo, incorporar suas características e costumes, mas inevitavelmente questiona tais hábitos por ser um indivíduo híbrido, por estar dividido entre sua crença, cultura, formação, experiência previamente adquirida em outra comunidade. Dessa forma, o estrangeiro enfrenta uma constante luta entre o que aprendeu anteriormente e o que passa a aprender a partir do momento em que se insere nesse novo contexto. Associado ao fato de que a língua não lhe seja totalmente conhecida, ou talvez pouco dominada, ele frequentemente passa por situações de desvantagem. Pedir abrigo, favores ou ajuda, discutir, defender-se, desculpar-se, respeitar e transgredir leis e ser julgado em uma língua que lhe é estranha 
torna-se extremamente difícil para ele, que acaba por ter medo inclusive de ser considerado louco, incoerente, de não ser compreendido. Conforme vemos em um dos trechos do livro:

O estrangeiro, que desajeitado ao falar a língua, sempre se arrisca a ficar sem defesa diante do direito do país que o acolhe ou que o expulsa; o estrangeiro, é, antes de tudo, estranho à língua do direito na qual está formulado o dever da hospitalidade, o direito ao asilo, seus limites, suas normas, sua polícia, etc. Ele deve pedir a hospitalidade numa língua que, por definição, não é a sua, aquela imposta pelo dono da casa, hospedeiro, o rei, o senhor, o poder a nação, o Estado, o pai, etc. Estes lhe impõem a tradução em sua própria língua, e esta é a primeira violência. (DUFOURMANTELLE, 2003, p. 15)

A problemática em torno de situações envolvendo o estrangeiro nos leva às reflexões sobre a hospitalidade, algo que, segundo Derrida, deveria ser oferecido incondicionalmente, de forma automática e de nenhuma maneira excludente ao estrangeiro. Essa hospitalidade deveria vir em forma de abrigo, de ajuda, de amparo, sem que o estrangeiro precisasse nem mesmo identificar-se, como se fosse algo de direito garantido.

\begin{abstract}
... a hospitalidade absoluta ou incondicional que eu gostaria de oferecer a ele supõe uma ruptura com a hospitalidade no sentido corrente, com a hospitalidade no sentido condicional, com o direito ou o pacto de hospitalidade. Falando assim, e uma vez mais, nós estamos considerando uma pervertibilidade irredutível. A lei da hospitalidade, a lei formal que governa o conceito geral de hospitalidade, aparece como uma lei paradoxal, perversível ou pervertedora. Ela parece ditar que a hospitalidade absoluta rompe com a lei da hospitalidade como direito ou dever, com o "pacto" de hospitalidade. Em outros termos, a hospitalidade absoluta exige que eu abra minha casa e não apenas ofereça ao estrangeiro (provido de um nome de família, de um estatuto social de estrangeiro etc) mas ao outro absoluto, desconhecido, anônimo, que eu lhe ceda lugar, que eu o deixe vir, que o deixe chegar, e ter um lugar no lugar que ofereço a ele, sem exigir dele nem reciprocidade (a entrada num pacto), nem mesmo seu nome. (DUFOURMANTELLE, 2003, p. 23)
\end{abstract}

Se pensarmos que essa situação vivenciada por qualquer estrangeiro pode ser associada ao que acontece com alunos aprendizes de uma língua estrangeira, talvez possamos entender e evitar certas consequências do processo de aquisição da mesma. $\mathrm{O}$ principal objetivo do aluno quando inicia um curso de línguas é aprender a falar tal idioma, se comunicar, se tornar fluente, muitas vezes inclusive espelhando-se em seus professores, desejando ser, falar, se expressar como ele na língua estudada. Nesse sentido, é possível comparar o sentimento de vergonha, constrangimento e inadequação que o aluno de LEM sente em sala de aula com o que sente o estrangeiro quando fora de sua cidade ou país, descrito por Derrida durante sua conversa com Anne Dufourmantelle. Assim como também é possível fazer ligações entre essa aspiração que 
o aluno possui em relação à fluência comunicativa e o sentimento de querer ser como o nativo daquela nova cidade ou país no caso do estrangeiro.

No ambiente de sala de aula, fazer perguntas sobre o assunto, tirar dúvidas para a prova, solicitar a repetição de determinada explicação, pedir auxílio para pronunciar aquela palavra complicada, realizar as atividades solicitadas pelo professor, interagir com os outros colegas são desafios que muitos alunos não conseguem superar, o que os faz atingir um grau cada vez mais alto de frustração em relação ao idioma. Da mesma forma, muitas vezes um estrangeiro pode vir a se sentir frustrado, desapontado e até mesmo sem saber como agir em determinadas situações.

Em outras palavras, é possível afirmar que, não raras as vezes, o aluno que está aprendendo um novo idioma assume uma posição de estrangeiro em relação ao ambiente de sala de aula, e consequentemente ao seu professor, já que ao mesmo tempo que almeja ser fluente, se comunicar naquela língua, sofre com o sentimento de incapacidade e frustração por não conseguir superar certas barreiras.

Outra ponte que pode ser construída entre a realidade de sala de aula de LEM e a entrevista de Jacques Derrida em questão é o fato de o estrangeiro fazer muitos questionamentos, sempre procurar razões para situações que, às vezes, não entende:

\footnotetext{
... frequentemente é o Estrangeiro quem questiona. Ele carrega e dispõe a questão. Logo nos lembramos do Sofista. É o Estrangeiro que, precipitando a questão intolerável, a questão parricídio, contesta a tese parmenidiana, questiona o logos do nosso pai Parmênides. O Estrangeiro sacode o dogmatismo ameaçador do logos paterno: o ser que é e o não-ser que não é. Como se o Estrangeiro devesse começar contestando a autoridade do chefe, do pai, do chefe da família, do "dono do lugar", do poder de hospitalidade... (DUFOURMANTELLE, 2003, p. 7)
}

Devido aos constantes desapontamentos que muitos alunos enfrentam quando não conseguem evoluir no aprendizado da língua estrangeira, surgem várias dúvidas tão normais de serem ouvidas. Questionamentos acerca da eficácia do método de ensino, do livro didático, do esquema administrativo da escola, dos métodos de avaliação, da condução da aula pelo professor, de sua experiência na área, da necessidade de atividades extras proporcionadas pela instituição, dentre outras. Além dessas, outras contestações também podem surgir no que diz respeito a si próprio e suas limitações; considerações que aparecem motivadas pelo desejo de saber, de entender a razão de seu próprio insucesso. É precisamente durante esse processo de contestações, dúvidas e auto-afirmação que o professor precisa desempenhar uma função de suma importância para o aprendizado de uma língua estrangeira: a de colaborador. No capítulo 7 do livro 
Postmodernism and Education (USHER \& EDWARDS, 1996, p. 140), encontramos a seguinte afirmação:

\begin{abstract}
A tarefa do professor não é construída como sendo confinada unicamente ao provimento de significações culturais fixas, nem tampouco ao conhecimento profundo e experto de determinada disciplina. Assim, existe uma atitude mais liberal e tranquila relacionada ao ensino. O ensino é o momento do processo de aprendizado quando o conhecimento, em vez de ser expresso como prédefinido, é gerado durante a interação entre professores, alunos, conhecimento disciplinar e significados adquiridos através da experiência. ${ }^{25}$
\end{abstract}

É quando o professor assume efetivamente a posição de facilitador, que pode-se verificar a teoria da hospitalidade tomando forma dentro do contexto didático. Conforme o filósofo Jacques Derrida, todo estrangeiro deveria receber apoio, abrigo, orientação de qualquer pessoa no novo ambiente onde acaba de chegar. Em nossa sala de aula a lógica deveria ser a mesma: qualquer aluno deve receber orientação, explicação, feedback, independente se já estudou aquela língua antes, de que outra escola veio, se já teve oportunidade de viajar para fora do país, se teve facilidade ou não para aprender um novo idioma, de classe social, de idade ou de qualquer outro fator.

Cabe ao professor oferecer essa "hospitalidade" ao aluno, principalmente àquele que apresenta grandes chances de falhar durante os estudos. E qual seria esse aluno? Aquele que falta constantemente às aulas por motivo de viagem a trabalho, por exemplo; ou aquele que durante as atividades interativas demonstra receio de participar, deixando muitas vezes de realizá-las, ainda depois de algumas aulas com o mesmo grupo. Para tanto, o professor contará sempre com recursos para identificar pontos fracos a fim de ajudar tais alunos: através de constantes aberturas para a expressão oral, observações cuidadosas durante o desempenho dos alunos, seguidas de feedback apropriado, avaliações orais objetivas é possível atuar de forma eficaz para diminuir a sensação de extrema dificuldade que muitos alunos sentem. Cabe também ao professor tentar perceber antecipadamente quais serão esses alunos e qual nível de dificuldade terão antes mesmo de um contato mais prolongado com a turma, já logo durante as duas primeiras aulas com um novo grupo. Seria interessante se o professor possuísse sensibilidade suficiente, sem nunca deixar de lançar mão dos recursos acima

\footnotetext{
${ }^{25}$ The task of the teacher is not constructed as being confined solely to the purveying of fixed cultural significations and the 'master' discourses of disciplines. Thus there is a more relaxed and 'liberal' attitude to teaching. Teaching is a moment in the learning process where knowledge, rather than being conveyed as pre-defined, is created in the interaction between teachers, learners, disciplinary knowledge and experimental meanings.
} 
mencionados para detectar possíveis problemas de falta de confiança, medo, vergonha, constrangimento e assim poder evitar suposições precipitadas ou irremediavelmente tardias a respeito de um aspecto tão relevante como esse. Ainda no mesmo capítulo do livro Postmodernism and Education, verificamos a seguinte passagem:

\begin{abstract}
... quando pensamos na "realidade" da educação a relacionamos frequentemente com socialização ou individualização. Em outras palavras, a questão da educação em todas as suas várias formas é construída e consequentemente entendida em termos de uma oposição binária de "repressão X liberação". É em torno desta oposição que a discussão política sobre educação é repetidamente polarizada - os educadores conservadores reforçando uma corrente domesticadora (socialização / repressão) contra os educadores progressistas apoiando uma corrente emancipadora (individualização /liberação). ${ }^{26}$ (USHER \& EDWARDS, 1996, p. 140)
\end{abstract}

Ao aceitar que cada aluno possui características especiais e próprias e que ao mesmo tempo são sujeitos híbridos, visto que são aprendizes quando estão em sala, mas possuem suas profissões, suas atividades fora daquele espaço e que as desempenham com total destreza e propriedade, o professor começa a desempenhar o papel de facilitador mencionado anteriormente. Assumir que essas características podem na realidade ser um aspecto positivo para o ensino-aprendizagem é abrir espaço para a individualização dos pontos fortes de cada aluno, impedindo que imposições violentas e castradoras aconteçam e os desmotivem. De acordo com Derrida, essa violência, característica da filosofia ocidental, acontece em forma de tentativas de reduzir as diferenças à igualdade, fazer desaparecer qualquer traço heterogêneo dentre os sujeitos, instituindo assim limites permanentes e rígidos. Derrida descreve esse processo com uma busca por um único centro, por uma única verdade, que definiria algo sem opções de mudança, interpretação ou variação. Isso em sala de aula seria o mesmo que anular a capacidade produtiva de nossos alunos, imobilizando seus pensamentos e impulsos criativos. Segundo Usher \& Edwards (1996, p. 138, 139):

Todas as tentativas de conhecer a verdade através dos bastidores do sistema de significações que é a linguagem são tentativas de totalizá-la, englobá-la e controlá-la, são consequentemente formas de imposição violentas... Essa noção de violência parece ressoar produtivamente em relação à educação. Existe uma visão através da qual a educação pode ser observada como uma forma de violência institucionalizada, onde corpos e almas são disciplinados

\footnotetext{
${ }^{26}$ When we think of the reality of education it is often as being either about socialisation or individuation. In other words, the text of education in all its various forms is constructed and therefore understood in terms of a binary opposition of 'repression/liberation'. It is around this opposition that the political debate over education is repetitiously polarised - the educational conservatives stressing the socialization / repression pole of domestication, the educational progressives the individuation / liberation pole of emancipation.
} 
e controlados ... De acordo com Derrida, educação é um espaço onde a verdade é controlada e assimilada violentamente, onde a tendência dos signos de se referir a outros signos é forçadamente detida, significados são reduzidos a um único e determinado sentido, onde o outro é mantido sob o controle da razão, diferença reduzida a igualdade, uma "ameaça" domesticada e assim rendida de forma maleável e inofensiva. ${ }^{27}$

Assim como o aluno, o professor também é um sujeito híbrido, que uma vez já passou pelo papel de aprendiz, e ainda continua a experimentá-lo, já que a docência constitui-se como um constante aprendizado. É importante que o professor deixe a simpatia que existe dentro de si falar mais alto, simpatia essa que é caracterizada como um sentimento de não indiferença ao próximo, de consternação pela dificuldade alheia e de superação de seu próprio sentimento egoísta para que então se porte como um hospedeiro na forma proposta por Derrida, e então se abra às dificuldades dos seus estrangeiros mais próximos - os alunos. É preciso pensar na hospitalidade como sendo esse oferecimento de apoio incondicional que levará o aluno a acreditar mais em si mesmo e a aprender o novo idioma com mais confiança. É somente reconhecendo que o processo de ensino-aprendizagem de LEM necessita ser construído a cada aula e não somente pelo estudante, muito menos só pelo docente, mas, sobretudo através da interação das duas partes, que professores poderão ajudar efetivamente seus alunos a desenvolver as habilidades da língua e os alunos, por sua vez, alcançarão seus objetivos com o novo idioma. Conforme Jordão (2008, p.10):

Como sujeitos híbridos, alunos e professores são vistos como capazes de "operar, atuar" nas rupturas dos discursos autoritários (Bakhtin, 1981), conseguindo transformar - de forma contingente - esses mesmos discursos. A agência, vista de uma perspectiva discursiva pós-estruturalista, adquire diferentes tons se comparados com aqueles das batalhas revolucionárias pela liberação: ela não é baseada em uma autodeterminação, mas em diferença e conflito, concebidas como condições positivas que favorecem o desenvolvimento do aprendizado. Agência pressupõe abertura à diferença, percepção de pressões contextuais e formas estratégicas de se resistir a elas, assim como reflexão criativa, já que ela problematiza suas próprias suposições durante o encontro com outras formas de conhecimento. A agência, sob essa perspectiva, acontece nos discursos que podem, ao mesmo

\footnotetext{
${ }^{27}$ All attempts to know the real through 'getting behind' the system of significations that is language are attempts to totalise, to en-close and master it, and are therefore forms of violent imposition ... This notion of violence seems to us to have a productive resonance in relation to education. There is a sense in which education can be seen as a form of institutionalised violence, where bodies and souls are disciplined and controlled ... Following Derrida, education is a site where the real is mastered and assimilated violently, where the tendency of signs to refer to other signs is forcefully arrested, meanings reduced to a single, determinate meaning; where otherness is brought under the control of reason, difference reduced to sameness, its 'threat' domesticated and thereby rendered malleable and harmless.
} 
tempo, restringir e permitir - reforçar ou transformar - a construção de sentidos e representações do sujeito em práticas sociais concretas. ${ }^{28}$

Quando observamos nossos alunos assumindo posições de estrangeiros durante as aulas de LEM, são necessárias ações que visem proporcionar um ambiente agradável, "hospitaleiro", o qual venha liberá-lo das pressões que o impedem de obter êxito na aquisição do novo idioma. Para isso, é essencial valorizar as diferenças, a atmosfera heterogênea, a variação presente em qualquer ambiente de produção do conhecimento, proporcionando, dessa forma, interação e produção criativa durante a aula. Ao proporcionar abertura para que cada aluno contribua com sua experiência pessoal em sala, o professor, além de diminuir as possibilidades de frustração, também mostrará ao aluno que ele começará a deixar de ser um estrangeiro naquele ambiente. Para atingir tal objetivo o comprometimento é com certeza o fator mais decisivo, e isso representa estar atualizado com procedimentos didáticos e métodos de ensino utilizados pela escola em que leciona.

Quando Derrida descreve a busca de um único centro dentro do processo educacional, e defende a aceitação da heterogeneidade, das diferenças, ele também observa a outra face que a educação pode e deve ter.

\begin{abstract}
Ao mesmo tempo, entretanto, e educação também é um espaço onde os jogos dos sentidos escapam da violência do fechamento logocêntrico. $O$ processo educacional é aprisional e ainda, além disso, hermenêutico e crítico. Ele sempre possui o poder para questionar formas dominantes de conhecimento, explicações totalizadoras para assim retirar os véus que os mascaram. Ele tem o poder de questionar a posição do definitivo, do certo e do comprovado. É um espaço onde o jogo da diferença pode escapar da "imobilidade fundamental", e da "certeza assegurada", do fechamento logocêntrico, um espaço de infinita disseminação. A educação, assim como todas as atividades culturais é imersa em significações, além de ser formada por elas próprias. Os alunos trazem consigo experiências de seus históricos de vida, existe um contexto de significados aos quais se remetem durante o processo de aprendizado, e existe um conflito de sentidos entre os códigos experimentais, pedagógicos e culturais transmitidos através da grade curricular. A educação está sempre aberta ao jogo da diferença de sentidos mesmo que ainda assim esteja sujeita a tentativas de que esse jogo seja manipulado ou impedido de acontecer. ${ }^{29}$ (USHER \& EDWARDS, 1996, p. 139, 140
\end{abstract}

\footnotetext{
${ }^{28}$ As hybrid subjects, students and teachers are seen as able to "operate" in the fissures of authoritarian discourses (Bakhtin, 1981), being able to transform - contingently - these same discourses. Agency from a poststructuralist, discursive perspective, acquires different tones from those of revolutionary struggles for liberation: it is not based on self-determination, but on difference and conflict, conceived as positive conditions for learning to take place. It presupposes openness to difference, perception of contextual constraints and strategic forms of resisting them, as well as creative reflexivity, since it problematizes its own assumptions in the encounter with other ways of knowing. Agency in this perspective happens in discourses that can, at the same time, restrict and allow - reinforce or transform - the construction of meanings and subject representations in concrete social practices.

${ }^{29}$ At the same time, however, education is also a site where the play of meanings escapes the violence of logocentric closure. The educational process is incarceral yet also hermeneutical and critical. It always contains within itself the potential to question dominant forms of knowledge and totalising explanations
} 
Faz-se necessário ressaltar que, obviamente, as razões do insucesso de alguns alunos durante a aquisição de um novo idioma não vêm somente do fato de os mesmos estarem inseridos em um ambiente estrangeiro, mas de outros fatores como, por exemplo, a falta de tempo para estudar. Mas se estabelecermos relações entre a teoria da hospitalidade do filósofo francês Jacques Derrida e as várias situações que acontecem durante as aulas de LEM é possível observar que alunos e professores podem vir a assumir posições de estrangeiro durante o processo ensino-aprendizagem. Entretanto, quando trabalhando de forma a valorizar as diferenças e oportunizar interação e criatividade, tanto professores quanto alunos alcançarão objetivos e vencerão os obstáculos encontrados. No momento em que o professor admite que os alunos podem contribuir para o bom aproveitamento de todo o grupo, e mais ainda, quando lança mão de tal 'artifício', de modo a aumentar o nível de interação e troca de experiências em sala, está proporcionando novas possibilidades de aprendizado aos mesmos. Assim, age da mesma forma que o nativo agiria de acordo com a teoria da hospitalidade de Derrida, abrindo as portas para o estrangeiro, deixando que o aluno sinta-se a vontade para criar e se expressar na nova língua que está aprendendo.

Como resultado o índice de motivação tanto de alunos quanto de professores aumentaria razoavelmente, considerando-se que boa parte dos alunos não mais desistiriam de frequentar as aulas e que muito professores teriam diminuída a sensação de frustração que não raras as vezes sentem ao presenciar o insucesso de alguns alunos.

\section{REFERÊNCIAS}

DUFOURMANTELlE, Anne. (2003). Anne Dufourmantelle convida Jacques Derrida a falar da hospitalidade. São Paulo: Escuta.

JORDÃO, Clarissa M. (2008). A Postcolonial Framework for Brazilian EFL Teachers' Social Identities. Revista Electrónica en Lenguas Extranjeras No. 2.

and to tear away the veils within which these are enshrouded. It has the potential to question the status of definitive, the certain, and the 'proven'. It is a site where the play of difference can escape the 'fundamental immobility' and 'reassuring certitude' of logocentric closure, a site of endless dissemination. Education like all cultural activities, is immersed in and formed by significations. Students bring meanings with them from their life contexts, there is a context of meanings which they engage with through the process of learning and a conflict of meanings between the experiential, the pedagogic and the cultural codes transmitted through the curriculum. Education is always open to the play of difference in meaning yet always subject to attempts to en-close and fore-close this play. 
MANDEVILLE, Bernard de. (1723). A fábula das abelhas. Disponível em < http://economiapoliticabrasil.blogspot.com/2009/03/fabula-das-abelhas-debernard.html > (acessado em 25/07/2011)

SMITH, Adam. (1999). Teoria dos Sentimentos Morais. São Paulo: Martins Fontes.

USHER, R. \& EDWARDS, R. (1996). Postmodernism and Education. London: Routledge. 